of taking our specialty training to the next level by more effectively collaborating and solving these very difficult challenges.

Michael Mazzone, MD

Stoney Abercrombie, MD; Joseph Gravel Jr., MD;

Karen Hall, MDi, Grant Hoekzema, MDi

Stanley Kozakowski, MD, Benjamin Scbneider, MD;

Todd Shaffer, MD, Martin Wieschbaus, MD

NORTH

AMERICAN

PRIMARY CARE From the North American

RESEARCH

From the North American
Primary Care Research Group

Ann Fam Med 2011;9:468-469. doi:10.1370/afm.1304.

\section{NAPCRG PUTS THE INCREASE OF PRIMARY CARE RESEARCH FUNDING AT THE TOP OF THE PRIORITY LIST}

Most primary care physicians are well aware of the countless research studies across disciplines that show the strength of a country's primary care system is directly linked to its population's health status. When people have access to primary care, treatment occurs before more severe problems can develop. People who receive primary care also have fewer preventable emergency department visits and hospital admissions than those who don't. ${ }^{1}$ It also is linked to improved workforce productivity and lower overall health care costs. Yet, historically, research funding dollars have gone towards research of a specific disease, organ system, cellular or chemical process, not for primary care.

While this research is of importance, it does not help the greatest number of patients at the point where they receive the majority of their health care. In 2008, primary care physicians had more patient visits compared with other medical specialist groups or care settings; for every 100 people, there were more than 193 primary care office visits. ${ }^{2}$

It seems obvious that adequate funding for research in primary care is essential to inform practice that will in turn create better outcomes for patientsespecially given the number of patients treated in a primary care setting.

On the contrary, recent studies by the Robert Graham Center found that of the $\$ 95.3$ billion that the National Institutes of Health (NIH) awarded in research grants from 2002 to 2006 (including the 3 years after the NIH budget doubled), family medicine researchers received just over $\$ 186$ million-only about 2 pennies for every $\$ 10$ spent. Furthermore, nearly $75 \%$ of all grants to family medicine came from only 6 of the NIH's 24 funding institutes and centers, and one-third of the institutes and centers did not award any grants to family medicine. ${ }^{3}$

These numbers just don't add up to better health outcomes for patients. Despite having the most costly health system in the world, the United States consistently underperforms relative to other countries on most dimensions of performance. Very little is known about important topics such as how primary care services are best organized, how to maximize and prioritize care, how to introduce and disseminate new discoveries so they work in real life, and how patients can best decide how and when to seek care.

At the NAPCRG Annual Meeting in November 2010, NAPCRG leadership put funding for primary care research at the top of its priority list. The NAPCRG Advocacy Committee meets regularly to determine and execute tactics to further this cause. NAPCRG leadership is working diligently to increase awareness with key decision-makers and is calling upon government funding centers to bring the research funding model in balance with the increased reliance on primary care. They developed a set of key messages to be used when meeting with lawmakers and funding sources.

NAPCRG encourages primary care physicians and researchers to join this effort and utilize the messages below in advocacy activities.

\section{The Importance of Primary Care and Primary Care Research}

The overall health of a population is directly linked to the strength of its primary health care system. A strong primary care system delivers higher quality of care and better health for less cost.

Primary care provides a "medical home" and considers the whole person, as they exist in family, community, and population, including multiple illnesses, preventive care, health promotion, and the integration of mind and body.

Primary Care Is

- complex and comprehensive

- where most people first bring their symptoms and health concerns and have their first touch with the health care system

- where people develop healing, trusting relationships with their physician and other primary care providers

Primary Care Research Includes

- translating science into the practice of medicine and caring for patients

- understanding how to better organize health care to meet patient and population needs 
- evaluating innovations to provide the best health care to patients

- engaging patients, communities, and practices to improve health

The majority of health care takes place in primary care practices, and yet, the majority of research funding supports research of one specific disease, organ system, cellular or chemical process_-not for primary care.

Very little is known about important topics such as how primary care services are best organized, how to maximize and prioritize care, how to introduce and disseminate new discoveries so they work in real life, and how patients can best decide how and when to seek care

We call for additional funds to be allocated to primary care research

Kristin Robinson, Public Relations Specialist, North American Primary Care Research Group Jack Westfall, MD, MPH,

Professor, Family Medicine and Associate Dean of Rural Healtb/Director. High Plains Research Network, University of Colorado

\footnotetext{
References

1. Phillips RL Jr, Bazemore AW. Primary care and why it matters for U.S. health system reform. Health Aff (Millwood). 2010;29(5):806-810.

2. Centers for Disease Control and Prevention/National Center for Health Statistics. Table 1, Physician office visits, by selected physician characteristics. In: United States 2008 National Ambulatory Medi cal Care Survey and National Ambulatory Medical Survey. Hyattsville, MD: CDC/NHCS; 2008.

3. Lucan SC, Phillips RL Jr, Bazemore AW. Off the roadmap? Family medicine's grant funding and committee representation at $\mathrm{NIH}$. Ann Fam Med. 2008;6(6):534-542.
}

\section{AAFP}

Ann Fam Med 2011;469-470. doi:10.1370/afm.1310.

\section{DEALING STRATEGICALLY WITH THE RUC TO BOOST FAMILY PHYSICIAN PAYMENT}

Improving payment for the cognitive services family physicians provide undoubtedly is the most crucial and challenging issue the AAFP must resolve. The payment disparity between primary care and procedural specialties undermines every family physician who struggles to redesign and improve his or her practice in this economy, and it also drives medical students away from primary care.

The AAFP has been working on many fronts to rectify this payment disparity. One important part of that effort is to make sure the Centers for Medicare and Medicaid Services (CMS) receives recommendations on the relative values of Current Procedural Terminology (CPT) codes from experts who understand primary care. Unfortunately, that's not happening now to the extent necessary. The only body making recommendations to CMS is the AMA/Specialty Society Relative Value Scale Update Committee, commonly called the RUC.

From its inception in 1991, the RUC has been dominated by procedural specialties whose representatives don't fully understand the complexity of the cognitive services we provide. They also have a financial interest in keeping the values for procedural services high.

Furthermore, although the RUC's methodology functions well when it comes to valuing one procedural code against a similar one, the methodology is flawed when comparing cognitive services with procedural services. The methodology also values evaluation and management $(\mathrm{E} / \mathrm{M})$ visits the same as the $\mathrm{E} / \mathrm{M}$ visits of other specialties, not taking into account the multiple comorbidities family physicians typically deal with in their patients.

As a result, the RUC often undervalues cognitive services while leaving overvalued procedures alonean ongoing disaster for those in the Medicare fee-forservice system. Since fee-for-service will be at least a part of how family physicians are paid for some time to come, this has to change.

\section{Two-Pronged Policy}

For several years, AAFP policy on the RUC has called for 2 approaches. One approach is to reform the RUC itself with changes that include increasing the number of primary care seats; adding seats for external groups, such as consumers and employers, who would bring voices the RUC needs to hear; and instituting voting transparency for RUC members, who currently vote in secret.

But even if the RUC were reformed, it would still be limited because of the methodology it employs. Therefore, the second approach in the AAFP's policy is to advocate creation of an alternative, multistakeholder advisory group to provide recommendations to CMS in concert with recommendations from the RUC.

The AAFP has been open about our concerns with the RUC, working persistently through our RUC representatives and talking with AMA and RUC leaders to recommend solutions. We even wrote to CMS last year, urging changes in the RUC and the establishment of an alternative advisory group.

But we shifted strategy and went very public with our concerns on June 10, 2011 when we sent the RUC 